are discussing this particular subject. They are dealing more especially with symbols for electrical and magnetic quantities, but the system might with advantage be extended to embrace all important quantities in physical science, especially as the subject is receiving the attention of most technical societies with a view to some action being taken in the matter.

There are, however, two great difficulties which arise when we try to fix upon a standard notation.

The first is the difficulty of persuading a number of writers and readers who have become accustomed to a certain symbol for a certain quantity to change it in favour of an equally large number of writers and readers who have become accustomed to another symbol. For instance, in France and Germany the letter "I" commonly represents the strength of an electric current, while in England and America " $\mathrm{C}$ " is more commonly used.

In the second place, there are not enough letters in the two or three alphabets at our disposal to give a distinct symbol to each quantity, without resorting to the combination of more than one letter to form a single symbol. There is a great objection to this combination of letters, because the use of subscript letters and numbers is required for distinguishing between particular quantities of the same general kind. If, for instance, $C$ represents current, $\mathrm{C}_{a}$ might conveniently represent armature current, and $\mathrm{C}_{1}$ the current in circuit No. I. It would therefore not be good to take $\mathrm{C}_{a}$ to represent capacity, or any quantity other than an electric current.

There is, moreover, an objection to using letters at all to represent quantities in a universal notation, because, unless initial letters are used, there is no connection in the mind between the letter and the quantity, and the symbol is difficult to remember. We cannot always use initials, because the initial letters differ in different languages. For instance, in England " $\mathrm{R}$ " commonly stands for resistance, while in Germany it is more convenient to use " $W$ " for widerstand. Moreover, the same initial occurs for a great number of different quantites. For instance, " $R$ " might stand for resistance, reluctance, reactance, radius, \&c.

One way of avoiding the above difficulties would be to create a number of new symbols which could be printed by means of type like ordinary letters, and which would represent each physical quantity in a distinctive manner.

The question, however, arises as to whether a number of entirely new symbols would be acceptable to writers, readers, and printers alike, and the sub-committee on symbols appointed by the British section of the Commission has requested the writer to place his views publicly before the profession, with the view of obtaining sugges tions and criticisms as to the feasibility of such a scheme from as wide a circle as possible.

In choosing a symbol, we would try to make a very simple picture of something that reminds us of the quan tity in question. For instance, I might represent temperature. If we were told that this simple outline of a thermometer represents temperature, we would have no difficulty in remembering it. Similarly, / might represent force, and the various "forces" might be derived from it; for instance, \& electromotive force (conventional representation of lighting), and $\bigcap$ magnetomotive force.

It is not my purpose here to say what would actually be the best form of symboi for each quantity, but it is not a difficult matter to devise very simple characters which can be written quickly, casily, and with sufficient accuracy, and can at the same time assist the memory to connect them with the quantity for which they stand.

What would the printers say to the new type? The author has taken up this matter with a very large publishing firm, and is assured by their chief expert that 200 or 300 new types would be a small matter to a modern printer, who is already accustomed to deal with many hundreds of different founts, each of which contains from 50 to 120 different symbols. He estimates that a printer in a large way of business has at his command as many as 60,000 distinct types, differing from each other either in letter, size, body, or face. The addition of 200 or 300 more would be a drop in the ocean. The size of the new type could be standardised for most purposes, and it No. $202 \mathrm{I}$, VOL. 78 ] would only be in some special case that another size would be called for.

The setting up of the formulæ with the standard size of type would be simpler than with the present system, in which subscript letters are often unnecessarily introduced. One symbol under the present system sometimes consists of four or five letters.

If it be admitted that the introduction of new symools is advisable, the question arises, what shall the new symbols represent exactly? Shall the sign \& (temp.) represent temperature in any units, or shall it represent the number of degrees of temperature, measured by some scale agreed upon, and embodied in the definition of the symbol? If the system of units employed be not prescribed, fewer symbols would be required, and the general writer who now says vaguely, "Let T equal the temperature," would find the symbol sufficient for his purpose. But from the reader's point of view there is much to say in favour of a symbol which will embody in its definition a standard system of units. Any formula expressed in such symbols would be completely self-contained, and would be an exact statement of a physical fact. Until the units employed in any formula are known, the formula expresses only half its meaning. Perhaps some slight addition to the symbol, or even to the whole formula, might be used to indicate that the standard system of units is employed. Without that addition, the symbol would have a general meaning. For instance, \& might equal temperature, while f might indicate the degrees centigrade above the absolute zero. The name of the type might be the name of the physical units which it represents; for instance, for 4 we might read "volts."

If writers, printers, and readers who have any definite views as to the best method of devising a system of symbols would communicate with the author, they might assist in solving the many difficulties which arise in connection with this matter.

The Cottage, Leicester Road,

Hale, Altrincham.

\section{Linnæus's Authorities.}

I AM happily able to throw a little light upon the question raised by Prof. Karl Pearson in Nature of July 16 (p. 247). The citation he quotes is identical with that in the tenth edition of the "Systema Naturæ" (1756), p. 24 .

"Bont. jav. 84. t. 84." will be found in Piso, "De Indiæ utriusque re naturali et medica," Amst. 1658. fol. The bastard title following the engraved title-page has towards the bottom this line:- "Iacobi Bontii, Bataviæ in majore Java novæ medici ordinarii, ... " hence, no doubt, the form employed by Linnæus. This forms the third separately paged part of the volume, and on p. 84 is a woodcut of the "Ourang Outang sive Homo silvestris," \&c.

" Koep. itin. c. 86 " is doubtless " Kiöping (Nils Matson) En reesa genom Asia, .... \&c. Wisingsborgh, I667. 4to."; I am quoting from Drvander's Catalogue of Banks's Library, vol. i., p. 86.

"Dalin. orat. p. 5." is referred to in Amœn. Acad., vol. vi., p. 74 as "Dalin in oratione Acad. R. Holm. de hac: " \&c. I have not verified the actual speech, but it should not be difficult to run it down in the early volumes of the Handlingar.

Linnean Society, Burlington House, W.

\section{Elliptical Halos.}

IN Pernter's " Meteorological Optics" the explanation of haloes, based on a consideration of refraction and reflection in ice-crystals, is given at some length. In particular the elliptical halo described by Mr. Cave in NaTurs of July I6 (p. 247) is shown to be a form depending on the sun's altitude. If the sun is less than $25^{\circ}$ above the horizon, the phenomenon appears as two arcs touching the $22^{\circ}$ halo at its highest and. lowest points. For altitudes greater than $70^{\circ}$, it is indistinguishable from the $22^{\circ}$ circular halo.

It would be interesting to know if $\mathrm{Mr}$. Cave observed the transition from the elliptical to the circular form.

3 Devana Terrace, Cambridge, July 16.
E. GOLD. 